\title{
XXXVIII. On some new lines in the spark-spectrum of aluminum
}

\section{Gustav A. Hemsalech}

To cite this article: Gustav A. Hemsalech (1897) XXXVIII. On some new lines in the spark-spectrum of aluminum , Philosophical Magazine Series 5, 44:268, 289-291, DOI: 10.1080/14786449708621065

To link to this article: http://dx.doi.org/10.1080/14786449708621065

曲 Published online: 08 May 2009.

Submit your article to this journal $[\pi$

Џ Article views: 2

Q View related articles $\asymp$ 
formed the kathode. No difference in definition could be noticed; there was, bowever, a great actinic difference. Under the oscillatory nature of the leyden-jar discharge the electrodes become alternately positive and negative. Possibly some of the want of definition noticed in Röntgen photographs taken even with the aid of electrical machines may be due to the fact that the oscillatory discharge does not always emanate from the same point on the anode surface. A small anode should therefore give sharper images than one of a large surface.

What is supposed to be a resistance in the case of the voltaic are, and in the modification of this as seen in discharges from high-tension transformers and in powerful electric sparks, and presumably in lightning-discharges, is a polarization which produces a variable difference of potential at the spark-terminals.

The inconstancy of spar's potentials has been shown by Jaumann*. In working with a revolving mirror it is found that the spark-terminals have to be brightened in order to preserve the same spark-length. I was interested also to observe the effect of the surrounding medium upon the spark potentials. Platinum terminals in sodium vapour showed the polarizable condition; but there did not appear to be an appreciable change in resistance apart from this polarization. The same was true when bromine vapour surrounded the spark-terminals. In the case of Crookes tubes it is customary to apply heat if the discharge will not pass through the tube: and some makers provide a connecting receptacle filled with a substance which, on being volatilized, modifies the internal conditions of the tube. This modification is often spoken of as a diminution of resistance of the tube. It should be more properly termed a method of modifying the state of polarization of the electrodes.

Jefferson Physical Laboratory,

Harvard University,

Cambridge, Mass., U.S.

XXXVIII. On some New Lines in the Spark-Spectrum of Aluminium. By Gustav A. Hemsalech†.

W HEN doing some spectroscopic work a short time ago I observed some lines in the red, due to aluminium, which I believe have not been recorded before. With a small

* Wied. Ann. 1895, 1v. p. 656.

+ Communicated by Arthur Schuster, F.R.S. 
coil and a small leyden jar only two of them are visible, and they appear as short lines; but when using a large coil giving a 4 to 10-inch spark and a large jar these lines appear long and bright, and are easily seen. One essential point is that the electrodes should be thick and rounded off at the ends.

The wave-lengths of the two brighter lines were measured in two ways, viz. by a concave Rowland grating (25,000 lines per inch) and by the ordinary prism-spectroscope. With the grating the two lines appeared rather weak, and were difficult to measure even in the first-order spectrum. The referencelines I used were those of potassium, of wave-lengths $6911 \cdot 2$ and $6938 \cdot 8$ (Kaiser and Runge), which are obtained in the arc. The relative distances were measured by means of an eyepiece-micrometer, which was fitted with a pointer. Eight sets of measurements were made, and the wave-lengths calculated by simple proportion. The values obtained were:-

\section{$7042 \cdot 3$, \\ $7056 \cdot 7$.}

With a prism of ordinary flint glass having an angle of $60^{\circ}$ the aluminium-lines appeared very bright and sharp. For reference I used lithium 6708.1 (Rowland), and the two potassium-lines $7665 \cdot 6$ and $7699 \cdot 3$ (Eder and Valenta). Some of the iron-lines would probably have been more convenient for the purpose, but there was no arc-light available at the time. Greater dispersion than that obtained by one prism could not be employed very well on account of the great distance between the $\mathrm{Li}$ and $\mathrm{K}$ lines, and therefore the values for the wave-lengths cannot be considered very accurate, but they are near enough for identification. Ten sets of micrometer-readings of the apparent distances were taken on three different days, which agree fairly well with each other. From the mean values of these readings the wave-lengths were determined by the method of inverse squares and were found to be as follows :-

$\left.\begin{array}{r}\left.\begin{array}{r}7043 \cdot 0 \\ 7058 \cdot 8\end{array}\right\} \text { with reference to } \mathrm{Li} 6708 \cdot 1 \text { and } \mathrm{K} 7665 \cdot 6 \text {. } \\ 7042 \cdot 2 \\ 7058 \cdot 3\end{array}\right\}$ with reference to $\mathrm{Li} 6708 \cdot 1$ and $\mathrm{K} 7699 \cdot 3$.

The value for the first-the brighter one-agrees very well with that obtained by the grating.

For the next three lines a dense prism of Jena glass was employed, and in place of the potassium-lines the newly determined aluminium-lines were used for reference together with $\mathrm{Li} 6708 \cdot 1$. The greater dispersion-which is more convenient in observing close double lines-made this neces- 
sary, since the $\mathrm{K}$ lines were not in the field of view at the same time as the $\mathrm{Li}$ line. The mean values taken for the wave-lengths of the Al lines used for reference were 7042.5 and 7057.9 respectively. Five sets of measurements were made and the wave-lengths obtained as before. They were found to be :-

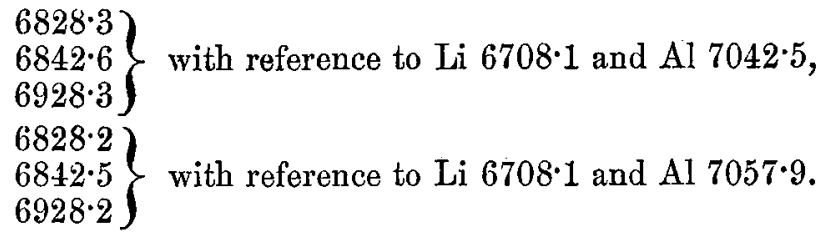

The following table gives the mean values for the wavelengths of the aluminium-lines and their relative intensities approximately, putting the intensity of the lithium-line as it appeared in the same field of view as 10 .

$\begin{array}{ccc}\text { Wave-length. } & \begin{array}{c}\text { Relativo intensity } \\ \text { and character. }\end{array} & \begin{array}{c}\text { Oscillation-frequency } \\ \text { reduced to vacuo. }\end{array} \\ 6828 \cdot 2 & 4 \text { sharp. } & 14641 \\ 6842 \cdot 6 & 4 \text { sharp. } & 14610 \\ 6928 \cdot 2 & \text { 2 nebulous. } & 14430 \\ 7042 \cdot 5 & \text { 6 sharp. } & 14195 \\ 7057 \cdot 9 & 5 \text { sharp. } & 14165\end{array}$

The line 7057.9 is probably double, the two components being very near together, but no accurate measurements were obtained. - A large Ruhmkorff-coil by Apps, giving a 10-inch spark, was used in these determinations, also a large leyden jar.

Before concluding I must express my thanks to Professor Sehuster for his valuable suggestions and the interest he has taken in the work. My thanks are also due to Mr. A. T. Stanton for the kind assistance he has rendered in working with the grating, and for many useful hints.

The Owens College,

July 15, 1897.

XXXIX. Intelligence and Miscellaneous Articles.

OBSERVATIONS ON LATIMER CLARK'S STANDAKD CELL WHEN CLOSED. BY THEODOR WULF.

THE Author observes the tension at the terminals of closed 1 normal elements by connecting up a condenser, and then discharging it through a galvanometer. By using Hicke's apparatus these observations can be made for very short intervals after 